\title{
Una perspectiva histórica de la política argentina frente al Brasil
}

\section{LAS RAÍ́GES HISTÓRICAS DE LA POLÍTICA EXTERIOR ARGENTINA}

La mayoría de los estudios sobre la política exterior argentina hechos por no argentinos han caracterizado la política de este país como individualista o aislacionista. En lo que se refiere a la participación de Argentina en los asuntos hemisféricos, no pocas veces los términos son más peyorativos: idiosincrásica o bien obstruccionista. Varios autores han dado a entender que los gobiernos argentinos deliberada y perversamente bloquearon todos los esfuerzos en favor de la cooperación hemisférica, debido a su celosa competencia por lograr un liderazgo con los EE. UU. O el Brasil, o por algunas xenofobias más generalizadas. En un reciente trabajo hecho por un australiano, éste califica la política exterior argentina como una reacción quejumbrosa e ineficaz a las iniciativas brasile${\tilde{n} a s^{1}}^{1}$ Las limitaciones de esta visión, por muy plausible que pueda parecer a primera vista, consisten en que ella no permite la existencia o expresión de un interés nacional argentino independiente de los deseos u objetivos de los $\mathbf{E E}$. uU. o el Brasil, y que se trata de una visión anacrónica, porque ignora la posibilidad de que los principios básicos de la política exterior argentina estén fundamentados en experiencias nacionales del siglo $\mathrm{xrx}$, cuando los EE. UU. eran tan sólo un factor menor en las relaciones internacionales de Argentina y el poder brasileño era materia de debate. Por consiguiente, necesitamos de una perspectiva más amplia acerca de la política exterior argentina, de manera que podamos entender mejor las relaciones de esa nación con otras, especialmente con el Brasil, evaluar más inteligentemente los asuntos actuales pendientes entre esos dos países y proyectar con mayor precisión las posibles respuestas argentinas a situaciones de conflicto. Este ensayo intenta proporcionar tal perspectiva por medio del rastreo de las raíces históricas de la conducta internacional de Argentina y por la identificación de los principios que son la base de su política exterior. Al hacerlo así, deberé hablar extensamente de las relaciones de Argentina con Ios EE. UU., puesto que gran parte de la política argentina del siglo $\mathrm{xx}$ con respecto al Brasil fue formu-

${ }^{1}$ Glen Barclay, Struggle for a Continent. The Diplomatic History of South America, 1917-1945. N. Y.: New York University Press, 1972). 
lada en el contexto de las relaciones triangulares con lOS EE. UU, y el Brasil, y la formulación de la política exterior de Argentina demostraba una preocupación por los EE. UU.

El punto más lógico para comenzar una visión histórica de las relaciones exteriores de una nación es el momento de su independencia. ¿Cuáles fueron las hipótesis centrales sobre el mundo que trajeron consigo, desde su experiencia colonial, los líderes de la nueva nación? ¿Gómo dio forma la lucha por la independencia a la definición de la nueva nación y cómo condicionó su postura en los asuntos internacionales?

El primer episodio significativo en la creación de la nación argentina fue el intento británico, en 1806, de arrebatar a España el control del Río de la Plata. La milicia criolla jugó un papel crucial en la contención de las fuerzas invasoras. Esta "reconquista", como fue Ilamada, constituyó una fuente de orgullo local y un símbolo de la resistencia al dominio extranjero ${ }^{2}$. Esta fue la primera definición del patriotismo argentino, que fluyó en forma natural de la experiencia colonial en la cual el dominio extranjero había sido una característica central. Los criollos del Río de la Plata se volvían cada día más inquietos bajo el dominio español y buscaban cómo expandir el área de decisiones sobre la cual tenían control directo. Otras lecciones que aprendió Argentina de su experiencia colonial fueron que las naciones más fuertes se ensañan con las más débiles y que raramente se respetan los tratados que se refieren a los derechos políticos o legales.

La lucha por la independencia de España conformó la nación argentina en el sentido más literal, ya que tenía que ver con la definición de los límites de la nación. Aquellos que eran instrumentales en el movimiento habían dado por seguro desde el principio que la nueva nación abarcaría el territorio del Virreinato del Río de la Plata. La presencia militar española en el altiplano de Perú (y Bolivia) desafió esas aspiraciones y en ese momento Paraguay y Uruguay establecieron su autonomía regional. Finalmente, Bolivia hizo lo mismo. Los líderes argentinos continuaron abrigando la creencia de que deberían ejercer control sobre todos los territorios que había incluido el virreinato.

El caso de UTruguay era especialmente delicado, puesto que envolvía una confrontación directa con el Imperio portugués y, más

'Los argentinos tienden a considerar la temprana resistencia brasileña a la penetración extranjera - la invasión holandesa $\mathrm{y}$, más tarde, la tutela británica- como experiencias criticas y formativas, que explican el confiado sentido de su identidad nacional por parte del Brasil. Sin embargo, raramente se acređita a la Reconquista el mismo impacto en la autoconfianza argentina. Ver Garlos Pérez Llana, "Potencias intermedias o países mayores? La política exterior de Argentina, Brasil y México". Estudios Internacionales $N^{\circ} 29$ (1975) pp. 62-3 y 80-87. 
adelante, con el Brasil. Tan pronto como lo permitió su situación económica y militar, Argentina intentó imponer su voluntad al Uruguay. Fracasó, y las circunstancias de este fracaso tuvieron importantes consecuencias para el desarrollo de la política exterior de la nación. Primero, colocó los asuntos exteriores directamente dentro de la política interna y fijó las líneas retóricas entre los nacionalistas y los internacionalistas para los ciento cincuenta años posteriores. El Gobierno liberal unitario bajo Bernardino Rivadeneira, al enfrentarse con la ruina financiera, intentó negociar un retiro de las fuerzas en el Uruguay. La oposición federal denunció este intento como antipatriótico y antinacional y aprovechó el episodio para ventaja suya en la política interna, relacionando la imitación unitaria de los modelos europeos de progresismo con su falta de patriotismo. Los federales no recapturaron el Uruguay, pero establecieron un modelo xenófobo para las futuras aserciones del nacionalismo y la soberanía argentinos. Hay que recordar, sin embargo, que la xenofobia, ni en ese entonces ni ahora, significa una aversión al contacto internacional o un retroceso a la autarquía.

La segunda consecuencia importante de la campaña uruguaya fue el éxito que obtuvo Gran Bretaña al forzar tanto a la Argentina como al Brasil a aceptarla como un estado valla entre ellos y establecer así un balance regional de poder en la costa este de Sudamérica, garantizado por el poder británico. La intervención británica, que estuvo basada en su capacida'd comercial y manufacturera $y$ en su poder naval, simbolizó el reemplazo de España por Gran Bretaña como el factor externo predominante en el desarroIlo argentino.

Guando los federales consolidaron su poder bajo Juan Manuel de Rosas, las relaciones exteriores habían estado dedicadas casi exclusivamente a la delimitación de las fronteras de Argentina. Si tomamos la política exterior como la expresión de los objetivos de una nación en sus relaciones con otras naciones, podríamos muy bien concluir que la nueva política de Argentina había sido notablemente poco exitosa. Bajo Rosas, el nacionalismo era, literalmente, la defensa de la nación. Al adoptar modelos importados para el crecimiento de Argentina y al invocar el apoyo externo en su campaña para derrocar a Rosas, la oposición liberal contribuyó aún más a la creencia en la dicotomía entre superpatriota-aliberal (más tarde, totalitario) por un lado, y cosmopolita-liberal (más tarde, democrático), por el otro. Esta dicotomía simplista ha dado color a la política argentina desde entonces y todavía afecta a la política externa.

Con el tiempo, Rosas fue derrocado con ayuda de una coalición internacional, y después de ello, durante casi diez años, la nación se mantuvo en el filo de la desintegración, en tanto que las fuer- 
zas regionales hicieron inútiles todos Ios intentos del gobierno central. Finalmente, fue una amenaza extema la que unió a la nación y puso fin a los regionalismos divisivos. Los liberales cosmopolitas, concentrados en la ciudad y en la provincia de Buenos Aires, impusieron su voluntad sobre las diversas provincias en el momento de zambullir a la nación en una guerra de cinco años con Paraguay. La campaña militar, si bien fue más larga y costosa de lo esperado, constituyó un factor importante en la consolidación de la nación. La vulnerabilidad del Uruguay, creada por conflictos destructivos y las pérdidas territoriales sufridas por Paraguay fueron lecciones importantes para el liderazgo argentino $y$ subrayaron la necesidad de la cohesión nacional.

El triunfo liberal sobre Rosas marcó la deliberada o consciente introducción en Argentina de un modelo positivista de crecimiento. Por medio de la inserción de Argentina dentro de la economía internacional de mercado, el país sería capaz de emular a los EE. UU. y a ciertas naciones europeas y de alcanzar los mismos niveles de civilización que aquellas naciones. Argentina sería rehecha en una imagen extranjera definida por la idea europea de progreso; los inmigrantes europeos poblarían las pampas y mejorarían la raza criolla, el capital europeo pagaria por la infraestructura necesaria para transferir los productos agrícolas de las pampas fértiles a los consumidores de Europa. Un programa semejante, destacaría no incidentalmente la superioridad de Argentina sobre el Brasil, una nación racialmente políglota, cuya economía dependía de la esclavitud y cuyo Gobierno estaba dirigido por un Emperador. Las normas bajo las cuales funcionaría la economía argentina serian aquellas del libre comercio liberal; las normas políticas bajo las cuales la población permanecería unida serían aquellas del constitucionalismo democrático anglo-americano.

El modelo de crecimiento funcionó y Argentina experimentó una bonanza económica de proporciones sin precedentes. A medida que se ponía más y más tierra en producción, Argentina se hacía cada vez más dependiente de los mercados europeos para la venta de sus excedentes de productos y del capital europeo para financiar ese comercio. Gran Bretaña era el principal poder extranjero en los asuntos foráneos y, año a año, una mayor proporción del producto nacional argentino se destinaba a satisfacer las necesidades de los inversores y consumidores británicos. Cada vez más, la economía argentina se moldeaba a las necesidades de la economía británica y en ese país eran tomadas las decisiones sobre la distribución de recursos en Argentina, por parte de aquellos que tenían en mente los intereses británicos antes que los argentinos; un modelo de dependencia que tiene algunos paralelos con la subyugación colonial a España. Para todos los intentos y 
propósitos, Argentina formaba parte de lo que ha sido llamado el imperio informal británico.

Sería una exageración decir que la política exterior argentina durante ese período de crecimiento buscó crear condiciones de dependencia estructural bajo Gran Bretaña, y sin embargo es correcto decir que el principal objetivo del Gobierno era facilitar la expansión de las exportaciones de la nación. En ese momento, se creía que el mecanismo de mercado iba a determinar la pauta de las relaciones entre las naciones. Argentina sería un país amigo, a la vez que políticamente independiente, de todas ellas, y seguiría las pautas de relación establecidas por el mercado internacional. La ocupación efectiva del territorio nacional, su frontera interior, era un objetivo concomitante, que se alcanzaba casi naturalmente y $\sin$ esfuerzo. El liderazgo argentino después de 1880 creía que los intereses de la nación requerían maximizar la exportación de sus productos agrícolas a los precios más ventajosos. Para conseguir tal fin, se realizarían todos los esfuerzos posibles en las relaciones internacionales. Había que evitar las limitaciones a la liberla práctica, ello significó no tomar compromisos internacionales tad de la nación que pudiesen inhibir el comercio con Europa. En formales.

Viéndola desde este aspecto, parece tanto lógica como razonable la cautela argentina en los primeros escasos encuentros panamericanos. Todo aquello que distrajera las energías de la nación de su relación con Europa era nocivo o inútil. Por consiguiente, el obvio dominio de los ex. UU. en el movimiento panamericano era poco amistoso hacia los argentinos. Para ellos, la tasa de crecimiento económico argentino significaba que su nación pronto se aproximaría $y$, sin duda, superaría los extraordinarios niveles de logro material de los EE. UU., y que ello se haría preservando al mismo tiempo los más altos valores de la civilización europea. Cualquier ventaja obtenida por el Brasil en esos encuentros era por lo tanto efímera y se podría esperar que se evaporase enfrentada con el crecimiento argentino. La carrera armamentista naval entre los dos estados fue un lamentable desperdicio, pero eso también habría de terminar una vez que Argentina sobrepasara al Brasil.

Había otras razones para la animadversión de Argentina hacia los consejos panamericanos. Si el objetivo central de su política exterior era la resolución o la disminución de la fricción política entre los estados, a fin de permitir la mayor libertad para el intercambio comercial, el establecimiento de relaciones institucionalizadas, tales como aquellas propuestas para la Unión Panamericana, tenían que ser consideradas negativas. La imposición de influencia económica por parte de una nación sobre la otra era considerado un hecho corriente. La imposición de influencia política de 
un estado sobre el otro era considerada anatema. El concepto argentino de soberanía estaba basado sobre experiencias concretas, en las cuales porciones de los territorios de la nación habian sido saqueados por poderes foráneos. La soberanía no podía ser comprometida por la cooperación en una organización hemisférica, particularmente en una dominada por un poder rival.

La resistencia a comprometerse con el movimiento panamericano no impidió que Argentina asumiera una posición activa en las relaciones internacionales entre las naciones hemisféricas, a medida que éstas cumplían sus ideales de desarrollo. Fue introducida la planificación estratégica, en tanto que misiones militares de diversos poderes europeos eran importadas a Argentina y a otras naciones latinoamericanas, para asegurarse de que los ejércitos estarían preparados para defender el territorio nacional. Tal como Alfred Thayer Mahan ha ejercido una tremenda influencia sobre aquellos que formularon las políticas en los EE. UU., así también en Argentina, hombres como Estanislao Zeballos tuvieron numerosos seguidores por sus nociones, muy similares a las de Teodoro Roosevelt, sobre geopolítica y preparación. Zeballos, que fue tres veces Ministro de Relaciones Exteriores, casi precipitó una confrontación armada con el Brasil acerca de la competencia naval. El el último minuto, el Presidente José Figueroa Alcorta decidió que la paz era más importante e hizo salir del Gabinete al Ministro Zeballos.

Esta postura agresiva que representaba Zeballos constituyó una posición minoritaria en la política exterior argentina. La actitud más común se caracterizaba por una cautela extrema, por la dedicación a la letra y al espíritu de la ley internacional, por el moralismo y la firme convicción de que el destino de la nación estaba ligado más estrechamente a los asuntos europeos que a los americanos. Dado este enfoque tradicional, eurocéntrico, un Presidente individual o un Ministro de Relaciones Exteriores podía proporcionar una fuerte corriente de idealismo al comportamiento de los asuntos exteriores argentinos. De allí que José Luis Mirature, Ministro de Asuntos Exteriores en la administración de Victorino de la Plaza (1914-1916) se uniera de buen grado con el Brasil y Chile en un intento (1915) para ser mediadores en las diferencias entre México y los EE. uU., que habían creado dificultades a la administración de Wilson, y luego participara en una serie de tratados entre los poderes ABC, destinados a garantizar la paz en el Continente. Pocos meses más tarde, Argentina respondió con entusias. mo a la propuesta de Wilson para crear una Liga Americana de Naciones. Si bien el idealismo jugó sin duda un papel importante en la decisión de apoyar la iniciativa de Wilson el hecho de que una Liga tal podría hacer disminuir el ritmo de la carísima carrera armamentista, atrajo a los líderes argentinos. Ellos pensa- 
ron que una Liga de este tipo daría a Argentina una posibilidad de liderazgo en el Hemisferio Sur, sin desbaratar los lazos económicos de la nación con Europa.

El estallido de la guerra en Europa constituyó un gran golpe para el sistema económico argentino. El país descubrió con gran desilusión que, en momentos de crisis, su relación con Gran Bretaña era fundamentalmente diferente de aquella que mantenían con ella los miembros formales del Imperio. Argentina fue tratada como cualquier otro país extranjero cuando los británicos dejaron de exportar carbón y capital, limitaron los movimientos de los embarques e impusieron severas restricciones a todas las importaciones. Argentina declaró su neutralidad en 1914, a pesar de las simpatías oficiales y no oficiales por la causa aliada. No había razón para hacer otra cosa. Todas las naciones del Hemisferio declararon su neutralidad.

Las mismas condiciones existían en octubre de 1916, cuando Hipólito Yrigoyen sucedió a Victorino de la Plaza. El nuevo régimen insistió en que su neutralidad sería "activa", diferente de la neutralidad "pasiva" de sus predecesores. Más importante que estas variaciones retóricas fue el que las condiciones de neutralıdad cambiaron dramáticamente cuando los EE. vu. entraron en la guerra en marzo de 1917, e hicieron un llamado a las naciones del Hemisferio para que adhirieran a la campaña para salvar al mundo para la democracia. Desde el punto de vista de Ios EE. UU., todas las naciones deberían haberlo hecho. Desde la perspectiva argentina, una declaración de guerra tendría que haberse basado en una justificación adecuada. Brasil adoptó la misma postura y declaró la guerra solamente después que varios de sus barcos fueron hundidos por los alemanes y éstós no pidieron disculpas. Después de la interrupción inicial del mercado internacional en 1914, los británicos habían restablecido sus nexos comerciales con Argentina y se había reanudado el flujo de productos a precios razonables. La interrupción del flujo de capital y de maquinaria pesada fue inconveniente, pero no amenazó el interés nacional como lo habría hecho un cese de las exportaciones. De la Plaza había diseñado un método para balancear el presupuesto por medio de préstamos internos de corto plazo (Notas del Tesoro), un expediente que Yrigoyen adoptó por el resto de la guerra.

Además del comercio en productos alimenticios, que los británicos seguramente continuarían realizando bajo cualquier circunstancia, el Gobierno argentino tenía tantas quejas contra los aliados como contra los poderes centrales. Las confrontaciones se desarrollaron a partir de las percepciones de Argentina sobre la violación de su soberanía y de su obstinada insistencia acerca de la letra de la ley internacional sobre los acuerdos frente a las disputas internacionales. 
Yrigoyen adoptó un enfoque idiosincrásico frente a las relaciones internacionales. Prestó poca atención al Protocolo o a las tradicionales sutilezas de la Diplomacia. Cuando creía que el derecho estaba de su parte, no se inhibía en sus acciones o en su lenguaje. Ordenó a un navío argentino saludar la bandera dominicana en Santo Domingo durante la ocupación de esa República por parte de los EE. UU. Propuso una Liga para los países latinoamericanos neturales en 1917, y en 1918 presentó un proyecto de un tratado latinoamericano de comercio. También ofreció proporcionar armas al Gobierno uruguayo, que estaba amenazado por una subversión interna, y extendió una mano fraternal de amistad hacia el Brasil. Desde el punto de vista de Ios EE. UU. estos actos, unidos a la neutralidad argentina, eran considerados como hostiles o negativos. Sin embargo, desde el punto de vista de Argentina, ellos eran actos inocentes. Yrigoyen no encontraba razones adecuadas para declarar la guerra a los poderes centrales. El aceptó y llevó a cabo el tradicional compromiso central con la exportación de productos agrícolas. EI comercio con los aliados era favorable durante ese tiempo de guerra. Había otros asuntos mucho menos importantes, y acciones que parecian caprichosas concernían tan sólo a materias de forma, que no tocaban la sustancia del interés nacional. Yrigoyen, tal como otros líderes que le precedieron o le sucedieron, al tratar de asuntos de menor importancia creyó que podía permitirse actuar en una forma que llamara la atención hacia sí mismo, conducta que otros podrían considerar intransigente o poco pragmática.

Puede decirse que la conducta de Yrigoyen frente a los asuntos exteriores representa el wilsonialismo. En ocasiones, tal como en la respuesta argentina a la Liga de las Naciones, pudo haber sido un wilsonialismo frenético. El Gobierno argentino estaba ofendido porque no se le había consultado sobre la formación de la Liga, y en el primer encuentro de la Asamblea de la Liga, pidió públicamente reformas drásticas que eliminarfan la distinción entre victoriosos y vencidos, entre estados grandes y chicos, y que convertirían la organización en un órgano de poder mundial verdaderamente democrático. Naturalmente, Ias propuestas fueron postergadas y la delegación argentina se retiró de la Asamblea con una colérica declaración que expresaba que su nación no podía, en conciencia, participar en una organización de victoriosos. El hecho de que el Brasil jugara un papel mucho más prominente en la nueva organización no provocó ni siquiera un murmullo por parte de los lideres argentinos. Para la mayoria, sin embargo, la meta era obtener un gran status de poder y las comparaciones con el Brasil reflejaban envidia.

Un ejemplo posterior de la conducta idealista e idiosincrásica en un foro internacional, que a menudo ha sido tomado como un 
antiamericanismo negativo por parte de Argentina, fue el criticismo público de intervención durante los debates de la Conferencia Panamericana de La Habana en 1928. Nuevamente, hay que recordar que el punto central era que los encuentros panamericanos no se consideraban vitales para el interés nacional argentino. Como consecuencia de ello, Honorio Pueyrredón, el representante especial a la Conferencia de La Habana, se sintió con la libertad suficiente para usar su participación para propósitos de política interna en Argentina. Allí trató de confundir al Presidente Marcelo $\mathrm{T}$. de Alvear, que se había pronunciado en contra de las políticas de Yrigoyen en un año de elecciones. Lo que es más, Pueyrredón estaba expresando su frustración frente al inquietante modelo de los EE. UU. de excluir los productos argentinos. En una prolongada serie de conflictos, un producto argentino después del otro fue excluido del mercado estadounidense por causa de problemas sanitarios o simplemente de tarifas exciusionistas. Si esta exclusión se hacía general o si los británicos la imitaban, las consecuencias para la economía argentina podrían ser desastrosas. En tanto los EE. UU. mantuviesen que la carne argentina estaba contaminada, las relaciones entre los dos países se verían afectadas. Pueyrredón intentó que el Gobierno de los EE. UU. comprendiera este hecho.

La gran depresión, que amenazó las bases mismas del bienestar económico argentino, colocó la política exterior en el foco de la política interna. Los mercados externos de la nación estaban en peligro a partir de 1929, y este era un tema que interesaba a todos los sectores de la sociedad. A lo largo de la década, el ajuste a la depresión fue debatido en la prensa y algunas de las decisiones específicas que se tomaron fueron el producto de intensas negociaciones y compromisos entre los grupos. Argentina no obtuvo todo lo que quería de sus relaciones internacionales, pero probablemente lo hizo tan bien como era de esperarse bajo estas circunstancias adversas.

Después de la Gonferencia de Ottawà en 1932, los británicos se volvieron cada vez menos comprensivos frente a las necesidades de Argentina e, inclinándose a la presión de sus dominios, impusieron una restricción después de la otra sobre los productos argentinos en el mercado británico. Los EE. UU. continuaron excluyendo la carne argentina y en diversas ocasiones añadieron insultos gratuitos a la injuria, excluyendo inclusive pequeñas cantidades de cereales que se necesitaban para corregir deficiencias temporales en el sistema de distribución de los EE. uU. Los representantes argentinos trataron de abrir nuevos mercados para los productos nacionales, pero los efectos fueron mínimos. En este contexto, el Pacto Roca-Ruciman con Gran Bretaña fue mejor que nada. Los térmi- 
nos del tratado eran nocivos, pero garantizaban un mercado para los productos argentinos a precios predecibles.

La lección principal extraída del estudio de la política exterior durante la depresión, como lo he escrito en otras partes, es que había tan sólo un tema importante que llamaba la atención del público argentino, que era la preservación de sus mercados de exportación, y que los demás temas podían convertirse en juguetes personales del Ministro de Relaciones Exteriores a de una élite sectorial particular ${ }^{3}$. Vista a esta luz, la neutralidad argentina en la Segunda Guerra Mundial, como su conducta durante la depresión y su neutralidad durante la Primera Guerra, estaba basada en la definición del interés nacional en términos de proteger los mercados de exportación y en la convicción de que la neutralidad, antes que el compromiso con uno u otro lado, era más conducente al logro de los objetivos nacionales. Esto no significaba que en Argentina no hubiese grupos que se inclinasen hacia el Eje: Los había. Más bien, yo argumentaría que las fuerzas pro-Eje dentro de la Argentina no dictaban la política de neutralidad. La politica era el resultado de un consenso bastante amplio dentro de la sociedad, incluyendo numerosos grupos que tenían sentimientos proaliados. La experiencia del Brasil durante este período no se perdió para el liderazgo argentino, especialmente para el militar. Uno de los programas más importantes del Presidente Agustín Justo fue una campaña de construcción de caminos que interpretarían mejor el "espacio" geográfico de la nación. El papel de los militares brasileños en la formulación de políticas económicas y la inclinación a crear una industria nacional de acero fueron objeto de intensa discusión en Buenos Aires. Pero permaneció el hecho de que el Brasil aún no era un asunto central en el pensamiento de la política exterior argentina y la lección que aprendió Argentina de las actividades brasileñas durante la depresión fue la habilidad de Vargas para sacar provecho de los alemanes y.de los americanos. Ellos intentaron. las mismas tácticas después que había comenzado la guerra, pero los EE. UU. ya no estaban dispuestos a jugar.

Justamente en los años precedentes al estallido de las hostilidades en Europa, el ambiente internacional se volvió desagradable para Argentina. El nexo imperial informal con Gran Bretaña ya no proporcionó el apoyo que Argentina necesitaba; los EE. UU. no querían o no eran capaces de ocupar el lugar que había tenido Gran Bretaña durante tanto tiempo; la habilidad para asegurarse materiales bélicos estaba siendo amenazada por Ia resistencia de los proveedores a vender algo a quien no fuese un aliado potencial vital, y Argentina no parecía probable de entrar en esa cate-

${ }^{3}$ Revista Argentina de Relaciones Internacionales, Año Ir, No 5 (1976). 
goría, tanto por su aislamiento geográfico como por sus actitudes políticas. Brasil estaba teniendo exito, puesto que había obtenido promesas de que se le enviarían armamentos y maquinaria pesada, tanto por parte del Eje como de los aliados y, como remache, las cosechas de 1938 y 1939 fueron o muy pobres o no se vendieron, provocando presiones financieras extremas en el Gobierno Federal.

La administración del Presidente Roberto Ortiz trató de revertir el flujo adverso de eventos y proyectar a Argentina hacia una posición crucial para los aliados, al proponer en abril de 1940 que todas las naciones americanas se uniesen para declarar su no beligerancia en la guerra europea. Se esperaba que Itamaratí ayudaría a convencer a los EE. UU. para que accedieran. Los EE. vu. despreciaron la propuesta y continuaron con su resistencia a cumplir con las demandas argentinas de material bélico y de apoyo económico. Ortiz se enfermó y renunció en favor de su Vicepresidente, Ramón S. Castillo. Castillo cayó, y después de un breve interludio fue reemplazado por Enrique Ruiz Guinazú, notorio admirador del "fascismo viril". Dada la configuración de las fuerzas polfticas internas en Argentina y las fuerzas internacionales, militares y económicas, realmente no había una alternativa viable a la neutralidad para Argentina después de $1940^{4}$.

A medida que aumentaba la presión para que Argentina se uniera a los aliados, la resistencia a esta presión ganó -justificadamente o no- Ia etiqueta de nacionalismo, y el nacionalismo unido a una inclinación por una autosuficiencia económica se vincuIó al antiliberalismo, tal como había sucedido medio siglo antes durante el régimen de Juan Manuel de Rosas. Los militares que derrocaron a Castillo en 1943 estaban preocupados porque Aroentina estaba cada vez más atrasada frente al Brasil en capacidad estratégica, y pensaban que para que Argentina fuese independiente a las amenazas a su soberanfa, era necesario imponer al país un programa de industrialización que le permitiera satisfacer sus propias necesidades de materiales estratégicos en épocas de crisis internacionales. El punto de vista militar sobre el interés nacional inclufa la preocupación por la posición geopolftica de Argentina en el Hemisferio, que había tenido el efecto de reafirmar la importancia de la competencia con el Brasil en base a las líneas indicadas por Zeballos a principios del siglo. Es interesante destacar que esta urgencia por competir no significaba unirse al esfuerzo de guerra de los aliados. Los axiomas tradicionales de política exterior conducian a proposiciones de carácter geopolítico; Argentina podía manejarse sola.

"Me he ocupado de este episodio en "The Argentine Proposal for NonBelligerancy, April 1940", The Journal of Interamerican Studies. Vol. XI, No 4 (1969), pp. 571-604. 
Después de 1943, Argentina y los EE. vu. ingresaron en un período en el cual sus relaciones eran difícilmente cordiales. No sólo Argentina había asumido una posición de neutralidad en una guerra en la cual los EE. UU. veían Ia neutralidad como una excusa para apoyar a los enemigos del Eje, sino que había abandonado toda pretensión de gobierno democrático $y$ estaba gobernada por militares que se sospechaba abrigaban simpatías por las formas alemanas o italianas de organización social fascista. El Gobierno estadounidense presionó insistentemente al Gobierno argentino, primero para que cooperara en forma más entusiasta en el esfuerzo de la guerra $y$, después de 1945, para que se conformara más estrechamente con las normas de conducta democrática aceptada. Esta presión exacerbó las relaciones entre los dos países en diversas ocasiones. EI elemento común en todos esos episodios es que cada vez que EE. UU. presionaba abiertamente al Gobierno argentino para que se condujera de una determinada manera, tenía el inesperado efecto de afectar a la facción polftica que demostraba más simpatías hacia los EE. UU. y de fortalecer la facción más nacionalista, más antiliberal y menos amistosa hacia los EE. U.. En otras palabras, interferir en los asuntos internos de Argentina había tenido el efecto, una y otra vez, de empujar al Gobierno más hacia la derecha y más hacia un nacionalismo xenófobo y lejos de una interacción razonable con los $\mathrm{EE}$. vU. y otras naciones del $\mathrm{He}$ misferio. Esta dicotomía, que fue el resultado de complejos asuntos internos, ha tenido implicancias significativas en las actitudes de la Argentina de hoy hacia el Brasil. Los mismos grupos cuyos puntos de vista políticos debieran hacerlos simpatizantes del actual régimen del Brasil son aquellos cuya definición geopolítica del interés nacional argumenta por una lucha darwiniana por la supremacía entre las dos naciones, $y$ aquellos que ven cada avance brasileño como un retroceso de Argentina. Esta ambigüedad ha producido considerable confusión con la burocracia argentina que toma las decisiones desde el golpe brasileño de 1964 .

Como contraste, valdría la pena mencionar un episodio en el cual la defensa vigorosa del interés nacional por parte de los elementos relativamente pro-Ex. uU. dentro del Gobierno argentino sirvieron para destacar su poder. En 1937, Franklin Delano Roosevelt ofreció siete viejos destructores al Brasil, para mejorar las relaciones con aquella nación sudamericana que los planificadores estadounidenses consideraban con mayor potencial de significancia estratégica. El Ministro de Relaciones Exteriores argentino, Carlos Saavedra Lamas, se quejó armargamente de este insulto gratuito a Argentina $y$ del peligroso riesgo que significaba la proposición de transferencia de armas para el balance de poder en Sudamérica. Hull reconsideró, y en último término retiró la oferta, 
aceptando vivir un momento difícil en las relaciones de los EE. UU. con el Brasil a fin de prevenir un deterioro en las relaciones con Argentina. EI éxito de esta defensa del interés nacional hecha por Saavedra Lamas tuvo el efecto de aumentar la fuerza de la facción democrática y proaliada, dirigida por el futuro Presidente Roberto Ortiz y que, en último término, condujo al intento que hizo el Ministro de Relaciones Exteriores Cantilo para atar más estrechamente a Argentina con los EE. Uv. a través del Pacto de No Beligerancia.

EI ostracismo argentino de la comunidad democrática infundió vida al enfoque que dio Perón a las relaciones exteriores. El llamó a su polf́tica la Tercera Posición, lo que significaba estar en un punto medio entre las polarizaciones de la guerra fría de un capitalismo imperialista (los EE. UU.) y un comunismo ateo (la URSS), y trató de afirmar el papel de Argentina en la política internacional en base a su postura neutral. Tal como sucedió con los esfuerzos de Yrigoyen treinta años antes, las iniciativas de Perón no fueron recibidas con entusiasmo por los EE. UU. Pero en el balance final, no fue la hostilidad de los EE. vo. la que debilitó la "tercera posición", sino que su falla para realizar sus grandiosos planes de industrialización y en alterar la dependencia estructural de la economía argentina.

Después que Perón fue depuesto en 1955, el primer Presidente elegido democráticamente, Arturo Frondizi (1958-1962), trató de estimular el crecimiento económico por medio de inversiones masivas en infraestructura, gran parte de ello con capital extranjero. Su política exterior dio énfasis a los asuntos hemisféricos en una forma en que parecía un retroceso a Ortiz y a Cantilo, anteriores a la Segunda Guerra Mundial. Gultivó la amistad de los EE. Uu., animó a Kubitscheck a proponer la Operación Pan Americana; fue uno de los principales apoyos que tuvo la Alianza para el Progreso; hizo un sagaz uso de los lazos personales entre su Ministro de Relaciones, Miguel Angel Cárcano, y la familia de John F. Kennedy. Al mismo tiempo, trató de hacer impacto en los asuntos hemisféricos al continuar manteniendo relaciones con la Cuba de Castro. Esto disgustó a los EE. Uu. y molestó a los militares, cuyas inclinaciones ideológicas eran hostiles a las doctrinas de cambio.

Aquí, tal vez, está la oportunidad para introducir otro ejemplo de cómo la presión de los ex. UU. en los asuntos argentinos y la competencia inexorable con el Brasil debilitaron la posición política de aquellos miembros del Gobierno que demostraban, dentro del contexto de la política argentina del momento, amistad hacia los EE. UU. y el Brasil. Frondizi Ilamó desarrollismo a su politica económica interna e intentó controlar el ingreso al país de inversiones extranjeras, para liberar a Argentina de su dependencia del capital externo. Esta política exigió una leve dosis de retórica na- 
cionalista, pero Frondizi era moderado en comparación con algunos de sus críticos nacionalistas que se oponían a toda inversión extranjera y que se mostraban escépticos frente a las virtudes del gobierno democrático. En abril de 1961, Frondizi firmó un Tratado de Amistad y Consulta con el Presidente del Brasil, Janio Quadros, en la ciudad fronteriza de Uruguayana. Esta aproximación con el Brasil fue parte de los esfuerzos de Frondizi para formar un bloque de países subdesarrollados y para usar la política exterior a fin de promover el desarrollo económico de su nación ${ }^{5}$.

La llave para la política hemisférica de Frondizi iba a ser su intento de arbitraje en las crecientes diferencias entre Cuba y los EE. UU. Al rechazar la iniciativa argentina y aumentar la presión para que Frondizi rompiera relaciones con Cuba, los EE. uU. lograron forzar la ruptura de relaciones pero, tal como en la Segunda Guerra Mundial, consiguieron su objetivo al costo de hacer el juego a los extremistas nacionalistas, que en este caso eran los militares que buscaban una excusa para liberarse de Frondizi. La combinación de la presión de los re. vU. y de sus propios militares forzó a Frondizi a romper relaciones con Cuba en febrero de 1962 y condujo, en un espacio de menos de un mes, a su derrocamiento por parte de los militares.

La política de Argentina en la década después de 1955 se ha caracterizado como un "un juego imposible". Los de la línea dura impidieron votar a los peronistas, lo que significó que todos los regímenes gobernaron sin la aprobación de esa porción del electorado. Una vez en el cargo, los gobiernos de minoría trataron de poner en efecto políticas sociales y económicas para hacer marchar la economía y se dieron cuenta que necesitaban la cooperación de un movimiento laboral altamente organizado. Para ganar este apoyo esgrimieron el incentivo de la participación política y prometieron mitigar las políticas económicas que pudieran afectar a los trabajadores. A medida que el Gobierno y los peronistas se acercaban unos a otros, Ios militares se ponían más cautelosos, hasta que no podían aceptar más la situación y derrocaban a los líderes elegidos, y el proceso se iniciaba nuevamente.

Durante este período, la política exterior no tenía un foco cla-

'La política fue explicada por el Subsecretario de Relaciones Exteriores en marzo del mismo año:

Argentina es un pafs latinoamericano, lo que significa que está hecho de un área geográfica perteneciente a los continentes subdesarrollados del mundo, pero tiene condiciones de negociación muy inferiores a aquellas de otras áreas por virtud de su menor significancia estratégica.. Nuestra actual solidaridad con América Latina se deriva no sólo de la tradicional simpatía por razón de sangre y lenguaje, sino también de la conciencia de que solamente la acción puede llamar la atención hacia nuestras necesidades, como se demostró, si bien en medida limitada, por el exito parcial obtenido por la Operación Panamericana. 
ro. Siempre era posible hacer un capital político agrupando al Gobierno en la derecha, asumiendo una postura aún más nacionalista, y el resultado era un aislamiento no tan espléndido, marcado por continuos ruelcos en la política.

En 1972, el General Alejandro Lanusse, que encabezaba la Junta Militar gobernante, eligio deshacer este nudo gordiano trayendo a Perón de vuelta al país. La principal tarea de Perón al asumir por segunda vez el Poder fue esencialmente la misma que había teniclo durante su primer régimen: cliseñar una estrategia para el desarrollo económico de la nación y sanar las heridas del cuerpo político. No tuvo el tiempo suficiente. Nunca forjó un consenso dentro de su propio movimiento y mucho menos en la mación como un todo, y su enfoque pragmático de las relaciones exteriores se cubrió de llamados retóricos a la camaradería con el Tercer Mundo, y el nacionalismo exacerbó las tensiones entre las secciones competidoras. El ala izquierda de su movimiento declaró su oposición al líder y se reanudaron las actividades terroristas que habían ayudado a convencer a los militares de devolver las riendas del Gobierno a Perón en primer lugar. La brecha se ensanchó después de la muerte de Perón en 1974. De López Rega, la èminencia gris del Gobierno de Isabelita, se decía que había estimulado la organización de brigadas de muerte derechistas prividas, que habían llevado a cabo actividades contra los terroristas. Las matanzas aumentaron entre 1975 y 1976, hasta que ello alcanzó la intensidad de una guerra civil no declarada. El imperio de la ley se convirtió en una burla. En marzo de 1976, los militares volvieron a asumir el Poder.

Además del tema de los derechos humanos, la política exterior del actual Gobierno encaja dentro del modelo tradicional. El Ministro de Economía, José Martínez de Hoz, quiere revivir la economía de exportaciones y el flujo de capitales externos hacia Argentina. Paralela a esos esfuerzos hay una tendencia hacia algún tipo de cooperación entre los regímenes militares del Hemisferio, que incluyen a Brasil, Uruguay, Chile, Bolivia, Paraguay y Perú. El General Jorge Videla decidió que cualquier forma de aislamiento era demasiado costoso para la posición debilitada de Argentina. Hasta la restauración de su fuerza nacional, él pareció haber olvidado las pretensiones intemacionales de Argentina y aceptado, al menos temporalmente, una posición subordinada al Brasil en las políticas de poder en Sudamérica. Al hacerlo así, ha incurrido en la ira de los geopolíticos, que ven la creciente influencia del Brasil en la Cuenca del Plata como una amenaza mortal a la soberanía argentina. Hubo evidencia de que esos partidarios de una política exterior agresiva estaban preparados para cooperar con los elementos -dentro de los militares- que no gustaban del enfoque tradicional de Martínez de Hoz frente al desarro- 
llo económico y que consideraban demasiado moderado a Videla. En la superficie, esto parece ser una alianza desafortunada, reuniendo a aquellos que créan en la democracia con aquellos que preferían formas totalitarias de organización social. Al escribir este trabajo, la crisis del Beagle ha creado un consenso nacionalista y ha distraído la atención del Brasil. En el caso que la diferencia con Chile sea arreglada en forma amigable o pospuesta, creo que mientras más tiempo gobiernen los militares, el continuo fracaso de Argentina para cumplir con las aspiraciones nacionales servirá para acelerar la tendencia hacia un nacionalismo en la política exterior, con una creciente influencia de los geopoliticos.

¿Qué significa esto para las relaciones de Argentina con el Brasil? No puedo decirlo con certeza. Mi mejor respuesta es resumir los principios que determinarán los parámetros dentro de los cuales se tomarán las decisiones ${ }^{\mathbf{6}}$ :

Pacifismo (probablemente es un mito tal como el principio de una política exterior, pero todos creen en él y sirve para inhibir el aventurerismo);

Aislacionismo (usado aquí en el mismo sentido limitado que se aplicaba a los EE. UU. en los años 20; se refiere a una fuerte aversión a tomar compromisos formales, si bien no a manejos económicos internacionales);

Moralismo (un tono que impregna la retórica de las relaciones exteriores argentinas bajo gobiernos de todo tipo y que tiene un modesto impacto en la política misma);

Sensitividad a la interferencia en los asuntos internos (estricta construcción en todos los temas de la intervención);

Adherencia a la ley internacional (un resultado directo del item precedente, usado para proteger a la nación en contra de la intervención);

Orientación europea (esto ha conducido a Argentina a asumir una actitud distante frente a los asuntos hemisféricos; debería advertirse que hay una posición constante de minoría en oposición a esto, que se enfoca en las consideraciones del balance de poder regional y en la lucha con el Brasil para influir en el Hemisferio, una posición que tiene menos influencia bajo los regímenes militares que bajo los gobiernos civiles);

Entre muchos otros, ver: Gustavo Ferrari, "Constantes de la Polftica Exterior Argentina", en Economic Survey, suplemento especial, Ne 1370 (febr. 27, 1973); Juan Carlos Puig "La Polftica Exterior Argentina y sus tendencias profundas", Revista Argentina de Relaciones Internacionales, I, I (Eneroabril 1975); Roberto Etchepareborda, "Presencia Nacional en el Exterior. Elementos de la Polftica de Ios Estados", suplemento de Respuesta Argentina (julio 1974); y Dardo Cuneo, "Argentina's Foreign Policy", en Carlos A. Astiz, ed. Latin American International Politics (Albany, 1969). Para una visión general, ver Celso Lafer y Félix Peña, Argentina y Brasil en el sistema de relaciones internacionales (Bs. As.: ediciones Nueva Visión, 1973). 
La oposición a los EE. UU. (a menudo resulta más de una o de otra de las constantes enumeradas anteriormente que de cualquiera hostilidad específica) .

\section{PERcepgIONES ARGENTINAS DEL BRASIL: UNA SÍNTESIS}

En este trabajo he argumentado, tanto implícita como explícitamente, que la mejor manera de entender el punto de vista de Argentina frente a sus relaciones con el Brasil, era entender la política exterior de la nación en términos generales. Para ese fin, he revisado las relaciones internacionales de Argentina desde la Independencia, definiendo los principios básicos o axiomas que han guiado su política exterior en el pasado y que probablemente guiarán su conducta en el futuro. Las predicciones, que siempre son arriesgadas, serían más confiables si fuesen consistentes con estos principios. Limitar el foco a los cambios de políticas de corto plazo sólo puede conducir a una confusión. En esta sección final, resumiré la política argentina hacia el Brasil e indicaré cómo esa política ha sido afectada por la política interna.

Hay tres escuelas de pensamiento argentinas más importantes concernientes al Brasil. Gada una de las tres tiene profundas raíces históricas y fuertes lazos culturales y políticos, a los que correspondía argumentar y formar coaliciones en favor de políticas y acciones específicas. He llamado estas escuelas la geopolítica, la tradicional eurocéntrica y la wilsoniana.

La escuela geopolítica, cuyo personero más articulado hoy en día es el General Juan E. Guglialmelli y la revista Estrategia, puede ser encontrada ya en los escritos y políticas de Estanislao Zeballos, si bien hay elementos de tal pensamiento en los planes de Alberdi para la consolidación nacional.

Los eurocentristas tienen la tradición histórica más rica. Representan la posición liberal que comienza con Rivadeneira y que ha dominado la historiografía y la política argentina desde Sarmiento y Mitre. Las figuras dominantes de la élite eran adherentes de esta escuela: Roca, Sáenz, Peña y Augustín Justo, y ella llegó a estar asociada con el modelo de crecimiento exportador. Políticamente, los geopolíticos civiles también habían sido miembros de la élite tradicional y del Partido Conservador, pero su obsesión con la expansión brasileña y su excesiva concentración en los asuntos hemisféricos constituía un motivo de molestia para los eurocentristas, que consideraban que los lazos comerciales europeos eran de tal importancia que la competencia con el Brasil no era sino una distracción cara. Las intromisiones en el territorio argentino no afectaron la zona económica decisiva, la pampa, y por eso no eran motivo de preocupación principal.

La escuela wilsoniana o idealista de asuntos internacionales tie- 
ne sus orígenes en el mismo eurocentrismo que el de los tradicionalistas. Los líderes argentinos, que rehusaban considerar que sus intereses nacionales estaban directamente relacionados con las amenazas a las naciones hemisféricas después de su independencia, respondieron en diversas ocasiones con llamados a un apoyo con altisonantes pronunciamientos sobre la naturaleza de la conducta internacional correcta. Estas declaraciones, que una vez fueron el lujo de una postura desinteresada, comenzaron a tener vida propia entre los principios abstractos de la política exterior de la nación. En el siglo $\mathrm{xx}$, muchos de aquellos que habian adoptado una postura wilsoniana en los asuntos internacionales, apoyando el constitucionalismo, la hermandad hemisférica, el desarme, la disminución de la tensión con el Brasil y la cooperación con los EE. UU., provenian del Partido Radical. Yrigoyen, Ortiz y Frondizi son tres de aquellos a los que me he referido. Más recientemente, Ricardo Balbín y el UCRP han seguido una línea yrigoyenista modificada en política exterior. Es una política que coincide con muchas de las actitudes que subrayan el enfoque liberal ortodoxo, representado por Martínez de Hoz, y que da un mayor énfasis al desarrollo regional y a la LAFTA. Las diferencias políticas han hecho casi imposible la cooperación entre los dos países; la fuerte inclinación populista de los radicales hace difícil tragar la medicina neoclásica que está siendo administrada por el régimen militar.

Con algunas interrupciones, la escuela eurocentrista dominó la política argentina hacia el Brasil desde 1860 hasta 1945. Después de esa fecha, en tanto que los voceros de esta escuela continuaban jugando papeles importantes en la formulación de políticas, su influencia fue muy decisiva en el legado de la amplia creencia concerniente al sector étnico más blanco de la nación, a su cultura europea superior y a su ventaja comparativa de producir alimentos para un mundo hambriento (por mandato divino). Estas creencias se pueden encontrar también entre los abogados de los enfoques wilsonianos y geopolíticos, e inhiben la cooperación con el Brasil.

Desde 1945, con el mayor peso de la influencia militar en el Estado y en la política exterior, la conducta de la nación en asuntos externos ha estado caracterizada por una mezcolanza eclectica de elementos tomados de las tres escuelas, cuyos abogados competían por influir más adentro del Gobierno. Este revoltijo dio como resultado una pronunciada inconsistencia en la conducta de las relaciones exteriores de la nación y un serio deterioro de la posición argentina en asuntos internacionales. Antes que una síntesis entre las escuelas, las líneas entre ellas han permanecido rígidas, de manera que las formulaciones de política exterior, como de política general, se han caracterizado por ese "juego imposible". EI grupo competidor ve cada decisión como una situación de suma 
igual a cero, en la cual el compromiso es inaceptable. Por consiguiente, el Gobierno se ve forzado a decidir entre opciones poco satisfactorias $y$, para estabilizar las fuerzas competidoras dentro de la sociedad y dentro del mismo Estado, oscilar de una opción contendora a la otra, en forma que los observadores externos consideran poco lógica y muy poco eficaz.

La situación no se ha perdido entre los estudiantes de la política exterior argentina y, ese hecho, junto con el poder actual de los militares, sugiere que la escuela geopolítica va a acrecentar su influencia en la formulación de políticas. Esta tendencia se verá acelerada por el éxito del Brasil en los asuntos internacionales y en el desarrollo económico. Como lo sugerí antes, la demora en resolver los problemas internos de Argentina fortalecerá la mano de los geopolíticos, y el fracaso en estabilizar la situación política de la nación también ayudará a los de la línea dura. La principal razón por la cual la política exterior bajo Videla no ha sido dinámica y agresiva es que no todos los de la línea dura son geopolíticos (algunos son antidemócratas pasados de moda, cuyas actitudes hacia el mundo permanecen más cercanas al punto de vista eurocentrista que al de los geopolíticos) y no todos los geopolíticos son de la línea dura, lo que debilita su posición negociadora dentro del régimen.

En su mayor parte, los geopolíticos argentinos consideran la política exterior del Brasil una parte integral del milagro brasileño, parte cel interés para terminar con el status subordinado de esa nación y Ilegar a ser uno de los más grandes poderes mundiales. Durante la década pasada, muchos comentaristas políticos de diversas posiciones han llegado a ver la política exterior del Brasil, la política económica e incluso el golpe de 1964 como manifestaciones de una visión geopolítica coherente del mundo que está detrás de toda acción emprendida por los militares brasileños en la persecución de la meta básica de su nación. De acuerdo con este punto de vista tan extendido, cualquiera sean las diferencias entre los líderes brasileños, ellos comparten esta perspectiva geopolítica, que está expresada muy claramente en los trabajos del General Golbery do Gouto e Silva. Este consenso es crucial para explicar el reciente éxito del Brasil; el liderazgo no sufre ninguna de las discordias internas que han plagado a Argentina. Aún más impresionante es que el consenso brasileño en lo concerniente a las metas nacionales ha operado durante años, algunos dicen que por siglos apoyado por un brillante servicio diplomático, y esa es la razón por la cual Brasil puede expandirse para llenar la masa de tierra continental, en tanto que Argentina, hasta hoy en día, no ha tenido éxito en establecer ciertas áreas fronterizas?

"Desde entonces (1494) hasta nuestros dias, una constante aparece sin in- 
De acuerdo con esta perspectiva argentina, las políticas expansionistas del Brasil reflejan las ambiciones naturales de cualquier nación estado y pueden ser apreciadas como tales, pero está perfectamente claro que el efecto de tal expansión es el encercamiento de Argentina y la frustración de sus justas aspiraciones. La respuesta al desafío del Brasil no es la hostilidad; la respuesta adecuada es un frente unido para apoyar objetivos claramente definidos. Aquí, por supuesto, está el problema. Los objetivos nacionales de crecimiento, seguridad y de un destino de importancia en los asuntos mundiales están virtualmente más allá del debate. Todavía constituye un problema interno complejo decidir sobre cuál es la estrategia más apropiada para lograr esos objetivos. Hasta 1976, los geopolíticos insistieron en el rechazo, de una vez por todas, del modelo de crecimiento exportador eurocéntrico con su foco exclusivo sobre la pampa. Ellos insistían en sustituirlo por un programa de industrialización que pudiera asegurar la fuerza del mercado interno, el bienestar de la fuerza laboral de la nación y el crecimiento de la demanda interna, que podría proporcionar el poder demográfico y económico para garantizar la ocupacıón etectiva de los territorios nacionales.

Desde el golpe de 1975, los rasgos desarrollistas de este esquema han sido objeto de considerable criticismo. Las políticas económicas de Martínez de Hoz son liberales ortodoxas y piden un éntasis renovado en las exportaciones agrícolas, para terminar con las nndustrias "artificiales" o "ineficientes" y retomar a una sanidad fiscal, inclusive si ello significara una declinación en la actividad económica en el corto plazo. En tanto que nadie defendería las polí. ticas del gobierno precedente, y los desarrollistas, civiles o militares, se retiraron del campo, la tensión entre las políticas económicas liberales y el fundamento de la geopolítica de un régimen militar nunca estuvo lejos de la superficie. Los imperativos de la seguridad nacional en el conflicto con Chile y el potencial conflicto con el Brasil fueron más importantes que los requermmentos de consistencia en la aplicación de las políticas liberales. Hasta 1978, estaba claro que las políticas de Martínez de Hoz se median por la cantidad de reservas en moneda dura acumuladas con el propósito de comprar armas modernas en el mercado abierto de Europa, para preparar a las fuerzas armadas de la nación para una posibie

terrupción en cuanto hecho histórico destacable allí tiene lugar: se trata del ansia expansionista hacia el oește, norte y sur de Portugal primero y de Brasil después, países que, valiéndose de una política de hechos consumados, apoyadas por un brillante servicio diplomático, fueron logrando los sucesivos reconocimientos diplomáticos internacionales de las conquistas territoriales efectuadas". De . Horacio P. Ballester, "Amazonia. El espacio brasileño de proyección continental", Estrategia, No 33 (marzo-abril 1975), p. 45. 
confrontación con Chile. El lazo entre el liberalismo económico y la lucha potencial con el Brasil es más ambiguo. Un elemento clave del exito de Brasil durante estos años ha sido la habilidad para establecer una ocupación efectiva en las zonas fronterizas y tener una presencia efectiva en el territorio de los estados vecinos. Argentina debe encontrar la manera de hacer lo mismo. Para evitar el control brasileño, Argentina debe insistir públicamente en la importancia del Cono Sur como un concepto estratégico. La Cuenca del Plata, que Brasil prefiere, coloca a Argentina en fuerte desventaja, porque no incluye todo su territorio nacional. Argentina debe encontrar una manera de hacer que Brasil entre a negociar para arreglar comprehensivamente los temas principales entre las dos naciones, especialmente los proyectos hidroeléctricos a lo largo del río Paraná, el control sobre la energía atómica y la amenaza proveniente de la influencia brasileña en el Uruguay, Paraguay y Bolivia. A no ser que se realicen esas negociaciones, una confrontación entre las naciones es una posibilidad. Si ellas pueden cooperar, si esas dos grandes naciones pueden crear una fuente de poder e influencia en los asuntos internacionales, ello tendría consecuencias de largo alcances.

${ }^{8}$ Estas ideas pueden extraerse de cualquiera de los artículos de Juan E. Guglialmelli, en Estrategia. Ver, por ejemplo, "Itaipú-Corpus. Operar en el frente principal y no confundirse con los frentes secundarios". No 33 (marzo: abril 1975); "Argentina-Brasil, enfrentamiento o alianza para la liberación", No 36 (septiembre-octubre 1975); y "Argentina, política nacional y política de frontera. Grisis nacional y problemas fronterizos", Nos 37/38 (noviembre 1975-febrero 1976). Para apreciar el grado hasta el cual estos conceptos geopolíticos básicos han permeado el pensamiento y los escritos sobre Árgentina y su relación con Brasil, ver La Nación, Io junio 1978 (Fernando de la Rua y Cesáreo T. Lachiondo), o las editoriales del 12 de octubre y del 16 de noviembre de 1978. Somos, Año 3, No 112, noviembre 1978 y Carta Politica, No 60 , noviembre 1978, pp. 5 y siguientes. 